\title{
Minor quinonoid naphthopyrones from apothecia of the lichen Ophioparma ventosa
}

Pierre Le Pogam ${ }^{1}$, Anne-Cécile Le Lamer ${ }^{1,2}$, Bandi Siva ${ }^{3}$, Béatrice Legouin ${ }^{1}$, Arnaud

Bondon ${ }^{4}$, Jérôme Graton ${ }^{5}$, Denis Jacquemin ${ }^{5,6}$, Isabelle Rouaud ${ }^{1}$, Solenn Ferron ${ }^{1}$, Walter

Obermayer $^{7}$, K. Suresh Babu ${ }^{3}$, Joël Boustie ${ }^{1}$.

${ }^{1}$ UMR CNRS 6226 ISCR PNSCM, Université de Rennes 1, 2 Avenue du Professeur Léon Bernard, 35043 Rennes, France.

${ }^{2}$ Université Paul Sabatier Toulouse 3, 118 Route de Narbonne, 31062 Toulouse, France.

${ }^{3}$ Division of Natural Products Chemistry CSIR, Indian Institute of Chemical Technology, Uppal Road, Hyderabad 500607, India.

${ }^{4}$ UMR CNRS 6226 ISCR ICMV, Université de Rennes 1, Plate-forme PRISM, CS 34317, 35043 Rennes, France

${ }^{5}$ UMR CNRS 6230, Chimie et Interdisciplinarité : Synthèse, Analyse et Modélisation (CEISAM), Université de Nantes, 2 Rue de la Houssinière - BP 92208, 44322 Nantes Cedex 3, France.

${ }^{6}$ Institut Universitaire de France, 1 Rue Descartes, 75231 Paris Cedex 05, France.

${ }^{7}$ Institut für Pflanzenwissenschaften, Karl-Franzens-Universität, Holteigasse 6, A-8010 Graz, Austria. 
I. Materials for pigment-enriched fraction.

S1. Positive-ion mode NanoHRESIMS profile of pigment-enriched fraction.

S2. Retrieved elemental composition of positive-ion mode NanoHRESIMS major peaks of pigment-enriched fraction.

II. Materials for ophioparmin (1)

S3. ${ }^{1} \mathrm{H}$ NMR $\left(\mathrm{CDCl}_{3}, 500 \mathrm{MHz}\right)$ of 1

S4. COSY spectrum $\left(\mathrm{CDCl}_{3}, 500 \mathrm{MHz}\right)$ of 1

S5. COSY/TOCSY spectrum $\left(\mathrm{CDCl}_{3}, 500 \mathrm{MHz}\right)$ of 1

S6. HSQC spectrum $\left(\mathrm{CDCl}_{3}, 500 \mathrm{MHz}\right)$ of 1

S7. HMBC spectrum $\left(\mathrm{CDCl}_{3}, 500 \mathrm{MHz}\right)$ of 1

S8. COSY (bold) and HMBC (arrows) correlations of $\mathbf{1}$

S9. NOESY spectrum $\left(\mathrm{CDCl}_{3}, 500 \mathrm{MHz}\right)$ of $\mathbf{1}$

III. Materials for 4-methoxyhaemoventosin (2)

S10. $\quad{ }^{1} \mathrm{H} \mathrm{NMR}\left(\mathrm{CDCl}_{3}, 500 \mathrm{MHz}\right)$ of $\mathbf{2}$

S11. COSY spectrum $\left(\mathrm{CDCl}_{3}, 500 \mathrm{MHz}\right)$ of $\mathbf{2}$

S12. HSQC spectrum $\left(\mathrm{CDCl}_{3}, 500 \mathrm{MHz}\right)$ of 2

S13. $\mathrm{HMBC}$ spectrum $\left(\mathrm{CDCl}_{3}, 500 \mathrm{MHz}\right)$ of 2

S14. $\quad \mathrm{HMBC}$ (arrows) correlations of 2

IV. Materials for 4-hydroxyhaemoventosin (3)

S15. ${ }^{1} \mathrm{H} \mathrm{NMR}\left(\mathrm{CDCl}_{3}, 500 \mathrm{MHz}\right)$ of 3

S16. HSQC spectrum $\left(\mathrm{CDCl}_{3}, 500 \mathrm{MHz}\right)$ of 3

S17. $\mathrm{HMBC}$ spectrum $\left(\mathrm{CDCl}_{3}, 500 \mathrm{MHz}\right)$ of 3

S18. HMBC (arrows) correlations of 3

V. Material for anhydrofusarubin lactone (4)

S19. ${ }^{1} \mathrm{H} \mathrm{NMR}\left(\mathrm{CDCl}_{3}, 500 \mathrm{MHz}\right)$ of 4

VI. Material for haemoventosin (5)

S20. ${ }^{1} \mathrm{H} \mathrm{NMR}\left(\mathrm{CDCl}_{3}, 500 \mathrm{MHz}\right)$ of 5

S21. Cytotoxicity of $\mathbf{5}$ using a panel of 7 cell lines 
S1. Positive-ion mode NanoHRESIMS profile of pigment-enriched fraction nESI 2777_MS_01 \#86 RT: 0.75 AV: 1 NL: $6.30 E 7$
T: FTMS + p NSIFull lock ms [50.00-750.00]

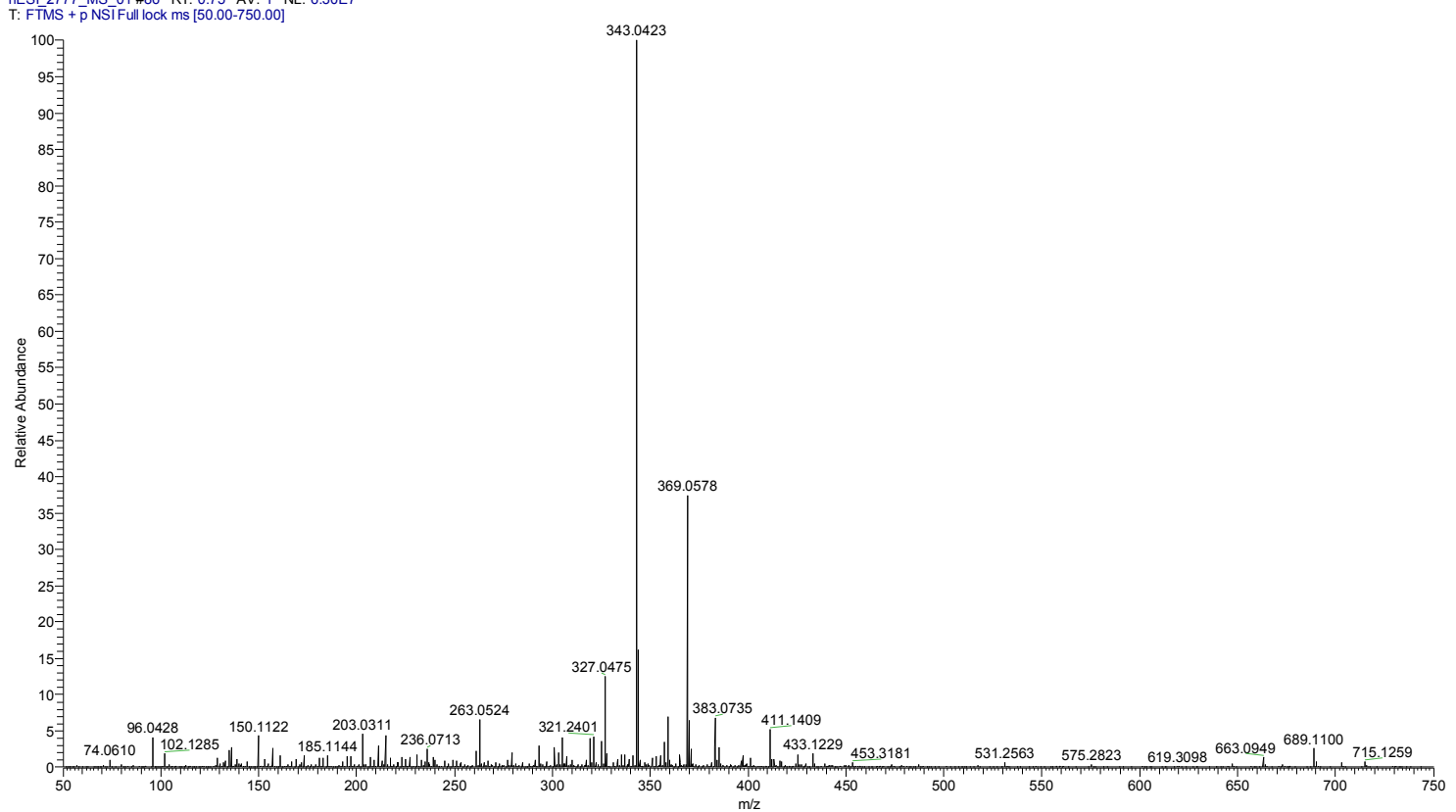


S2. Retrieved elemental composition of positive-ion mode NanoHRESIMS major peaks of the pigment-enriched fraction.

\begin{tabular}{|c|c|c|c|c|c|c|}
\hline $\mathrm{m} / \mathrm{z}$ & Intensity & Relative & Theo. Mass & Delta (ppm) & Composition & Identification \\
\hline 343.04235 & 56883868 & 100 & 343.04244 & -0.25 & $\mathrm{C} 15 \mathrm{H} 12 \mathrm{O} 8 \mathrm{Na}$ & 4-hydroxyhaemoventosin (3) \\
\hline 369.05785 & 21900272 & 38.5 & 369.05809 & -0.64 & $\mathrm{C} 17 \mathrm{H} 14 \mathrm{O} 8 \mathrm{Na}$ & Ophioparmin (1) \\
\hline 327.0476 & 7870470.5 & 13.84 & 327.04752 & 0.23 & $\mathrm{C} 15 \mathrm{H} 12 \mathrm{O} 7 \mathrm{Na}$ & Haemoventosin (5) \\
\hline 263.05243 & 6273552 & 11.03 & 263.05261 & -0.7 & $\mathrm{C} 11 \mathrm{H} 12 \mathrm{O} 6 \mathrm{Na}$ & \\
\hline 411.14102 & 4011858 & 7.05 & 411.14142 & -0.98 & $\mathrm{C} 21 \mathrm{H} 24 \mathrm{O} 7 \mathrm{Na}$ & Divaricatic acid \\
\hline 383.07352 & 3985133.8 & 7.01 & 383.07374 & -0.56 & $\mathrm{C} 18 \mathrm{H} 16 \mathrm{O} 8 \mathrm{Na}$ & \\
\hline 359.01628 & 3353377.8 & 5.9 & 359.01622 & 0.17 & $\mathrm{C} 18 \mathrm{H} 8 \mathrm{O} 7 \mathrm{Na}$ & \\
\hline 215.06749 & 3159354 & 5.55 & 215.06787 & -1.75 & $\mathrm{C} 11 \mathrm{H} 12 \mathrm{O} 3 \mathrm{Na}$ & \\
\hline 203.03107 & 3148826.5 & 5.54 & 203.03148 & -2.04 & $\mathrm{C} 9 \mathrm{H} 8 \mathrm{O} 4 \mathrm{Na}$ & \\
\hline 321.24012 & 2968336.8 & 5.22 & 321.24002 & 0.34 & $\mathrm{C} 18 \mathrm{H} 34 \mathrm{O} 3 \mathrm{Na}$ & \\
\hline 319.22446 & 2809529.8 & 4.94 & 319.22437 & 0.31 & $\mathrm{C} 18 \mathrm{H} 32 \mathrm{O} 3 \mathrm{Na}$ & \\
\hline 293.24491 & 2668366.8 & 4.69 & 293.2451 & -0.64 & $\mathrm{C} 17 \mathrm{H} 34 \mathrm{O} 2 \mathrm{Na}$ & \\
\hline 211.09374 & 2449126.3 & 4.31 & 211.09408 & -1.59 & $\mathrm{C} 9 \mathrm{H} 16 \mathrm{O} 4 \mathrm{Na}$ & \\
\hline 325.03195 & 2436766.5 & 4.28 & 325.03187 & 0.22 & $\mathrm{C} 15 \mathrm{H} 10 \mathrm{O} 7 \mathrm{Na}$ & Anhydrofusarubin lactone (4) \\
\hline 357.05797 & 2176772.8 & 3.83 & 357.05809 & -0.33 & $\mathrm{C} 16 \mathrm{H} 14 \mathrm{O} 8 \mathrm{Na}$ & 4-methoxyhaemoventosin (2) \\
\hline 157.08322 & 2123446.3 & 3.73 & 157.08352 & -1.86 & $\mathrm{C} 6 \mathrm{H} 14 \mathrm{O} 3 \mathrm{Na}$ & \\
\hline 305.24509 & 1913303.4 & 3.36 & 305.2451 & -0.02 & $\mathrm{C} 18 \mathrm{H} 34 \mathrm{O} 2 \mathrm{Na}$ & \\
\hline 303.22944 & 1844170.1 & 3.24 & 303.22945 & -0.05 & $\mathrm{C} 18 \mathrm{H} 32 \mathrm{O} 2 \mathrm{Na}$ & \\
\hline 371.07353 & 1807822.3 & 3.18 & 371.07374 & -0.56 & $\mathrm{C} 17 \mathrm{H} 16 \mathrm{O} 8 \mathrm{Na}$ & \\
\hline 231.02618 & 1791374.6 & 3.15 & 231.02639 & -0.93 & $\mathrm{C} 10 \mathrm{H} 8 \mathrm{O} 5 \mathrm{Na}$ & \\
\hline 261.08783 & 1720905 & 3.03 & 261.0886 & -2.95 & $\mathrm{C} 16 \mathrm{H} 14 \mathrm{O} 2 \mathrm{Na}$ & \\
\hline 261.10957 & 1646988.6 & 2.9 & 261.10973 & -0.59 & $\mathrm{C} 13 \mathrm{H} 18 \mathrm{O} 4 \mathrm{Na}$ & \\
\hline 197.07808 & 1521087.8 & 2.67 & 197.07843 & -1.76 & $\mathrm{C} 8 \mathrm{H} 14 \mathrm{O} 4 \mathrm{Na}$ & \\
\hline 279.22936 & 1452110.3 & 2.55 & 279.22945 & -0.33 & $\mathrm{C} 16 \mathrm{H} 32 \mathrm{O} 2 \mathrm{Na}$ & \\
\hline 185.11449 & 1424935.8 & 2.5 & 185.11482 & -1.77 & $\mathrm{C} 8 \mathrm{H} 18 \mathrm{O} 3 \mathrm{Na}$ & \\
\hline 385.03175 & 1400423.5 & 2.46 & 385.03187 & -0.32 & $\mathrm{C} 20 \mathrm{H} 10 \mathrm{O} 7 \mathrm{Na}$ & \\
\hline 335.21934 & 1377668.8 & 2.42 & 335.21928 & 0.18 & $\mathrm{C} 18 \mathrm{H} 32 \mathrm{O} 4 \mathrm{Na}$ & \\
\hline 195.09883 & 1348236.3 & 2.37 & 195.09917 & -1.75 & $\mathrm{C} 9 \mathrm{H} 16 \mathrm{O} 3 \mathrm{Na}$ & \\
\hline 173.07812 & 1337691.5 & 2.35 & 173.07843 & -1.77 & $\mathrm{C} 6 \mathrm{H} 14 \mathrm{O} 4 \mathrm{Na}$ & \\
\hline 383.31292 & 1324849.9 & 2.33 & 383.31318 & -0.68 & $\mathrm{C} 21 \mathrm{H} 44 \mathrm{O} 4 \mathrm{Na}$ & \\
\hline 239.16143 & 1323011.4 & 2.33 & 239.16177 & -1.41 & $\mathrm{C} 12 \mathrm{H} 24 \mathrm{O} 3 \mathrm{Na}$ & \\
\hline 207.09885 & 1241546.5 & 2.18 & 207.09917 & -1.54 & $\mathrm{C} 10 \mathrm{H} 16 \mathrm{O} 3 \mathrm{Na}$ & \\
\hline 223.13013 & 1234563.3 & 2.17 & 223.13047 & -1.49 & $\mathrm{C} 11 \mathrm{H} 20 \mathrm{O} 3 \mathrm{Na}$ & \\
\hline 197.11445 & 1192634.4 & 2.1 & 197.11482 & -1.86 & $\mathrm{C} 9 \mathrm{H} 18 \mathrm{O} 3 \mathrm{Na}$ & \\
\hline 225.10939 & 1186437.8 & 2.09 & 225.10973 & -1.51 & $\mathrm{C} 10 \mathrm{H} 18 \mathrm{O} 4 \mathrm{Na}$ & \\
\hline
\end{tabular}

Table S2 : Elemental compositions retrieved for all major peaks detected in positive-ion mode NanoHRESIMS. Lines outlined in blue refer to possible quinonoid naphthopyrones structures (i.e candidate compositions encompassing $\mathrm{C}_{12-20} \mathrm{H}_{8-20} \mathrm{O}_{5-10}$ ). 
S3. ${ }^{1} \mathrm{H} \mathrm{NMR}\left(\mathrm{CDCl}_{3}, 500 \mathrm{MHz}\right)$ of 1

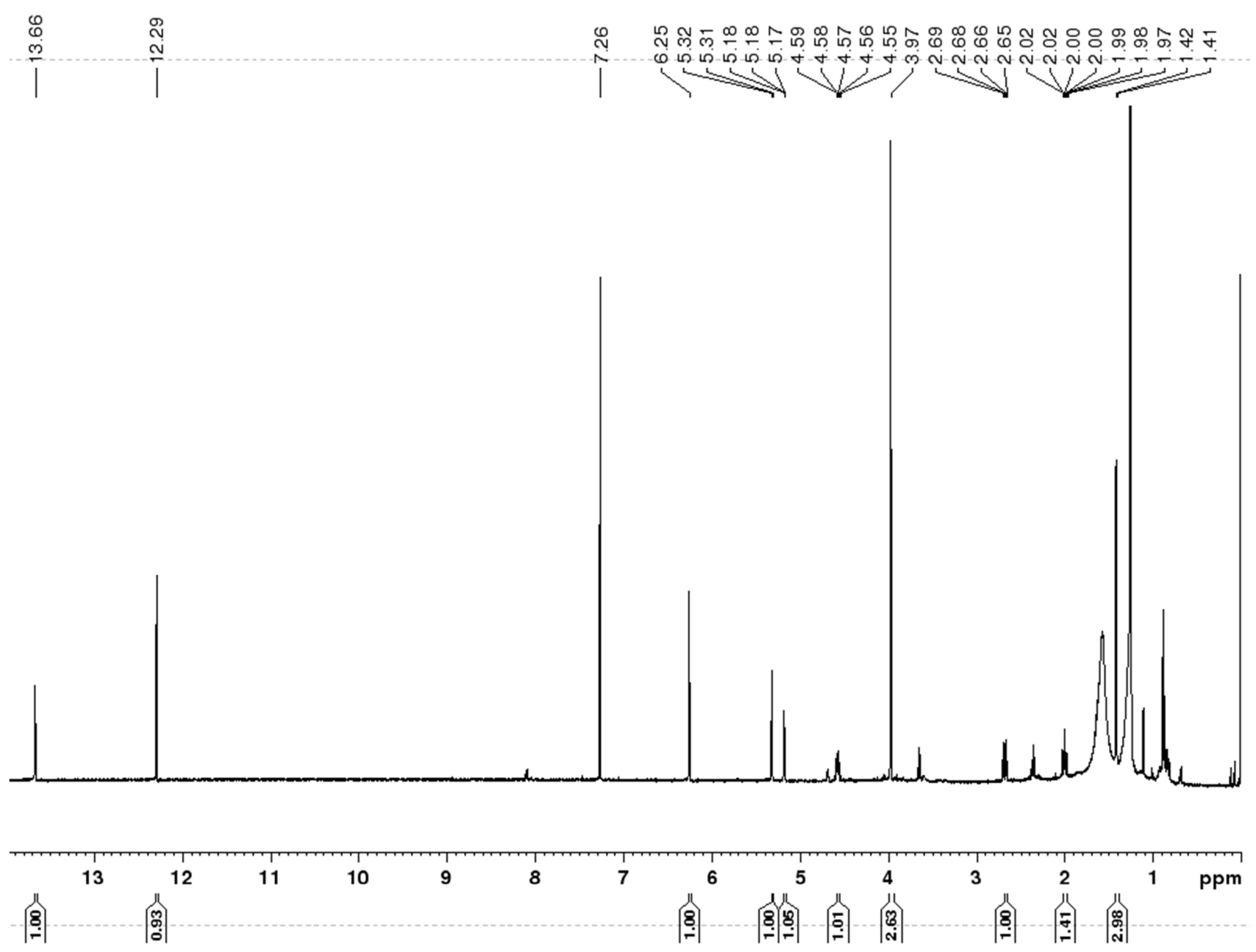




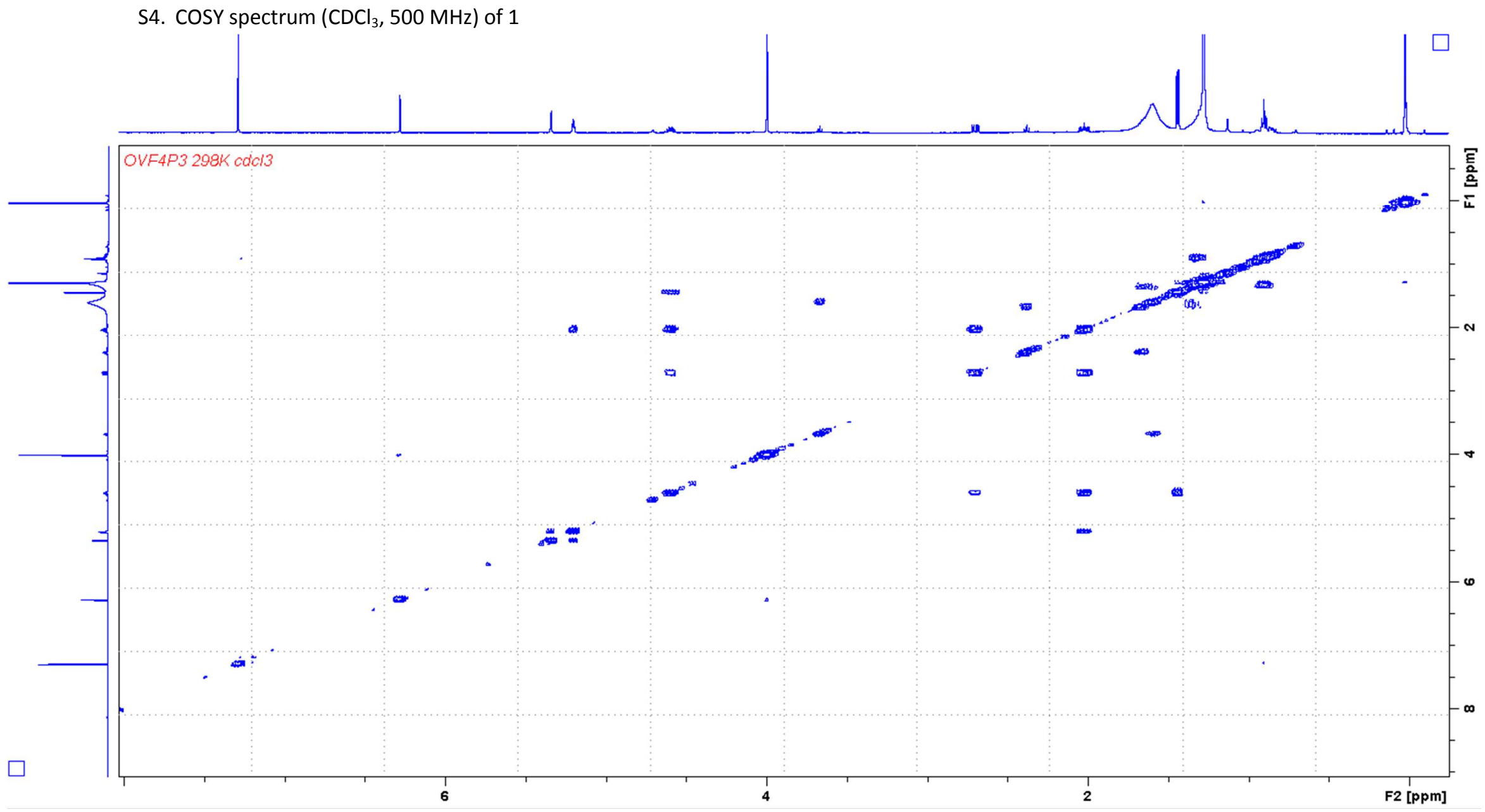


S5. COSY/TOCSY spectrum $\left(\mathrm{CDCl}_{3}, 500 \mathrm{MHz}\right)$ of 1

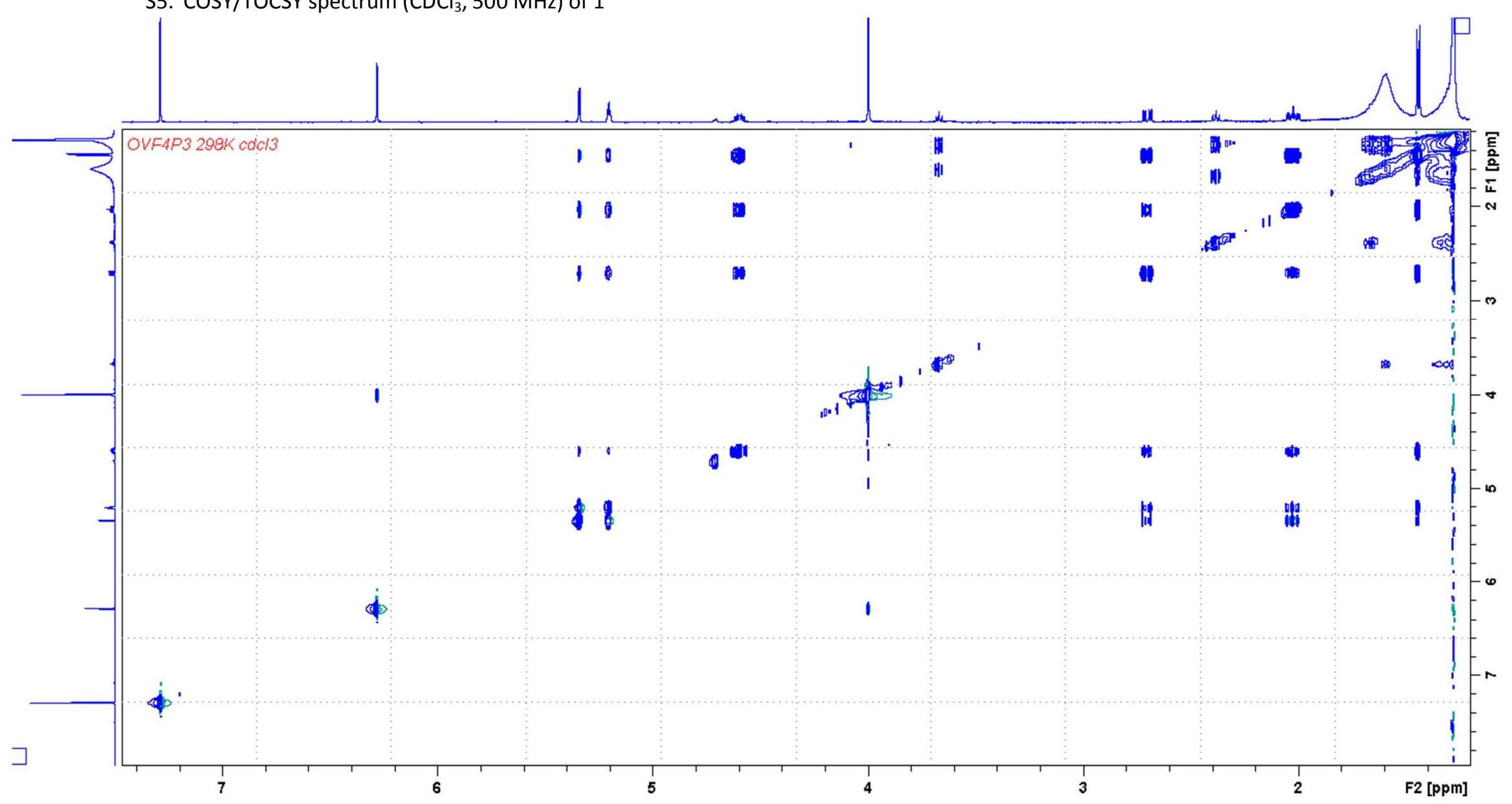


S6. HSQC spectrum $\left(\mathrm{CDCl}_{3}, 500 \mathrm{MHz}\right)$ of 1

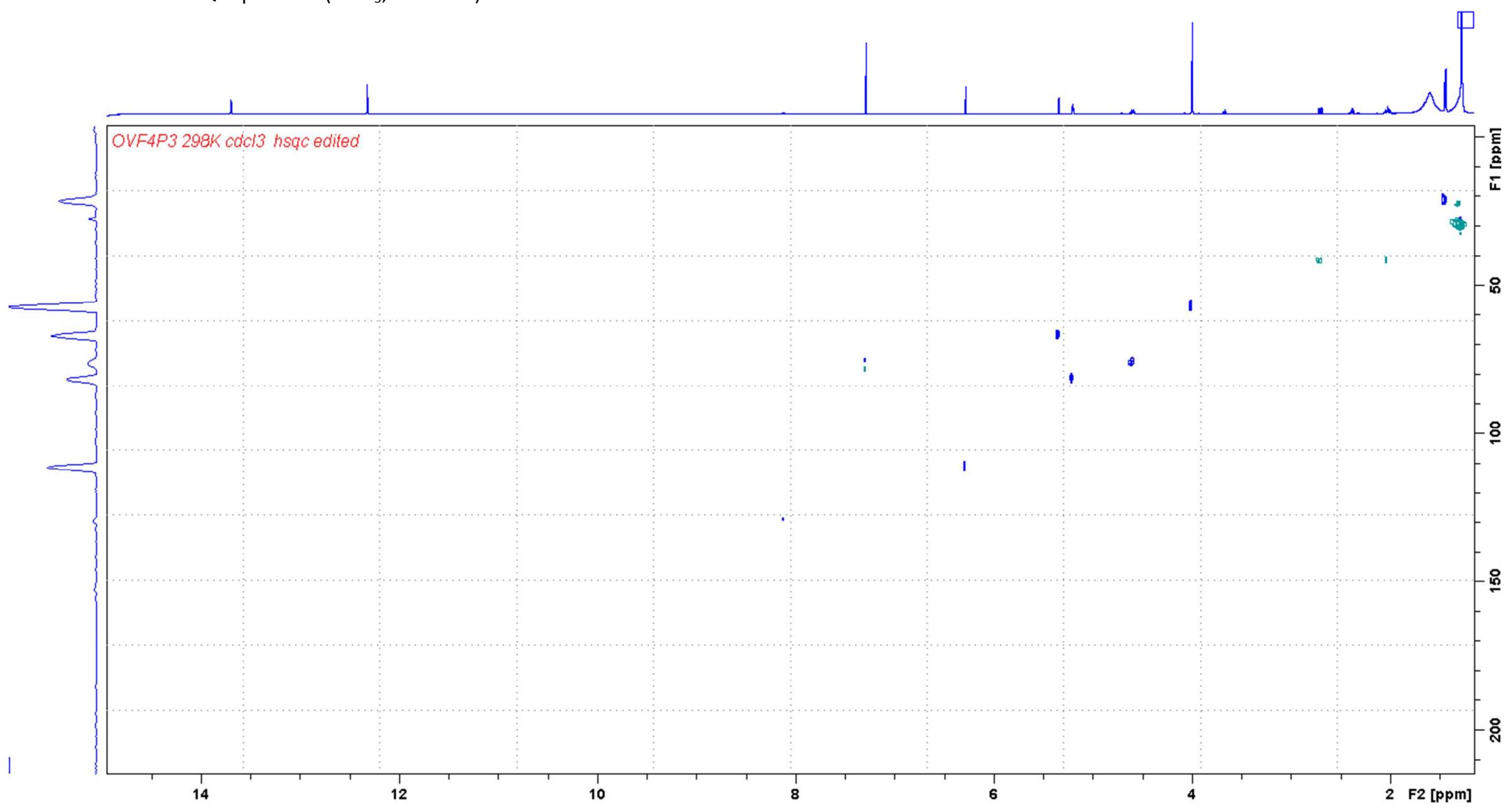


S7. $\mathrm{HMBC}$ spectrum $\left(\mathrm{CDCl}_{3}, 500 \mathrm{MHz}\right)$ of 1

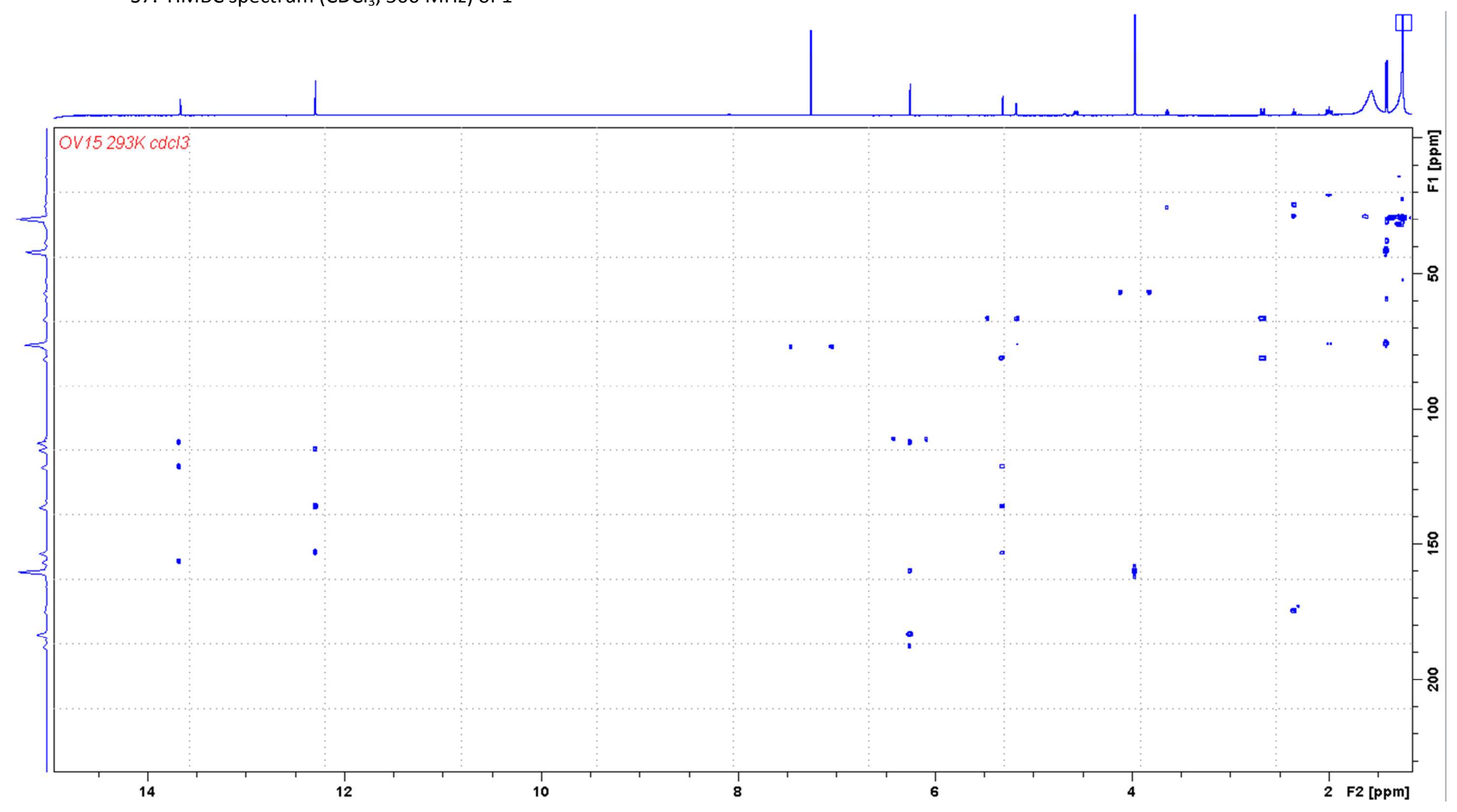


S8. Key COSY (bold) and HMBC (arrows) correlations of 1.



COSY

$\rightarrow \mathrm{HMBC}$ 
S9. NOESY spectrum $\left(\mathrm{CDCl}_{3}, 500 \mathrm{MHz}\right)$ of $\mathbf{1}$

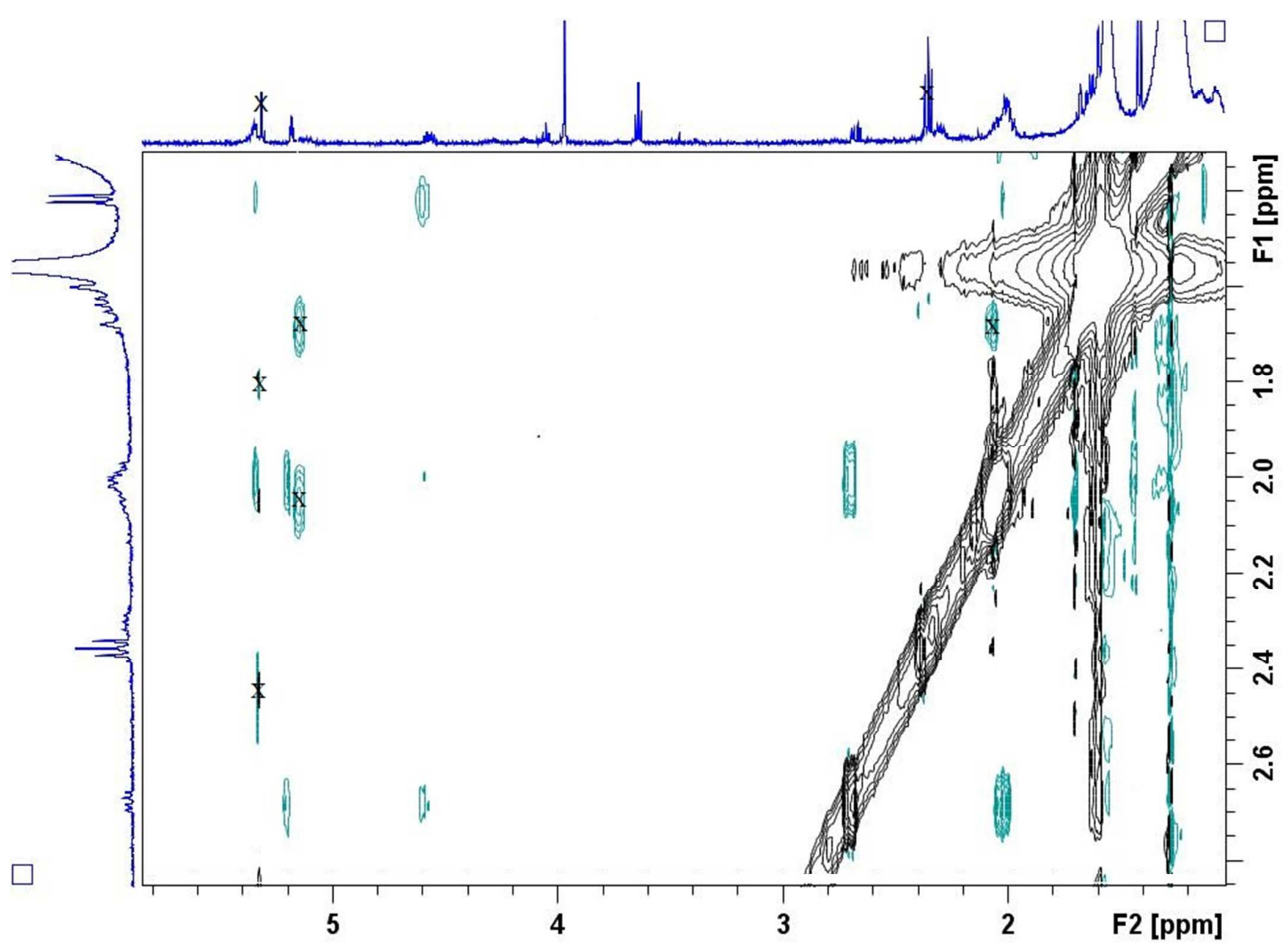

*Strikethrough signals refer to peaks appeared upon long storage of $\mathbf{1}$ thus not belonging to the native molecule. 
S10. ${ }^{1} \mathrm{H} \mathrm{NMR}\left(\mathrm{CDCl}_{3}, 500 \mathrm{MHz}\right)$ of 2
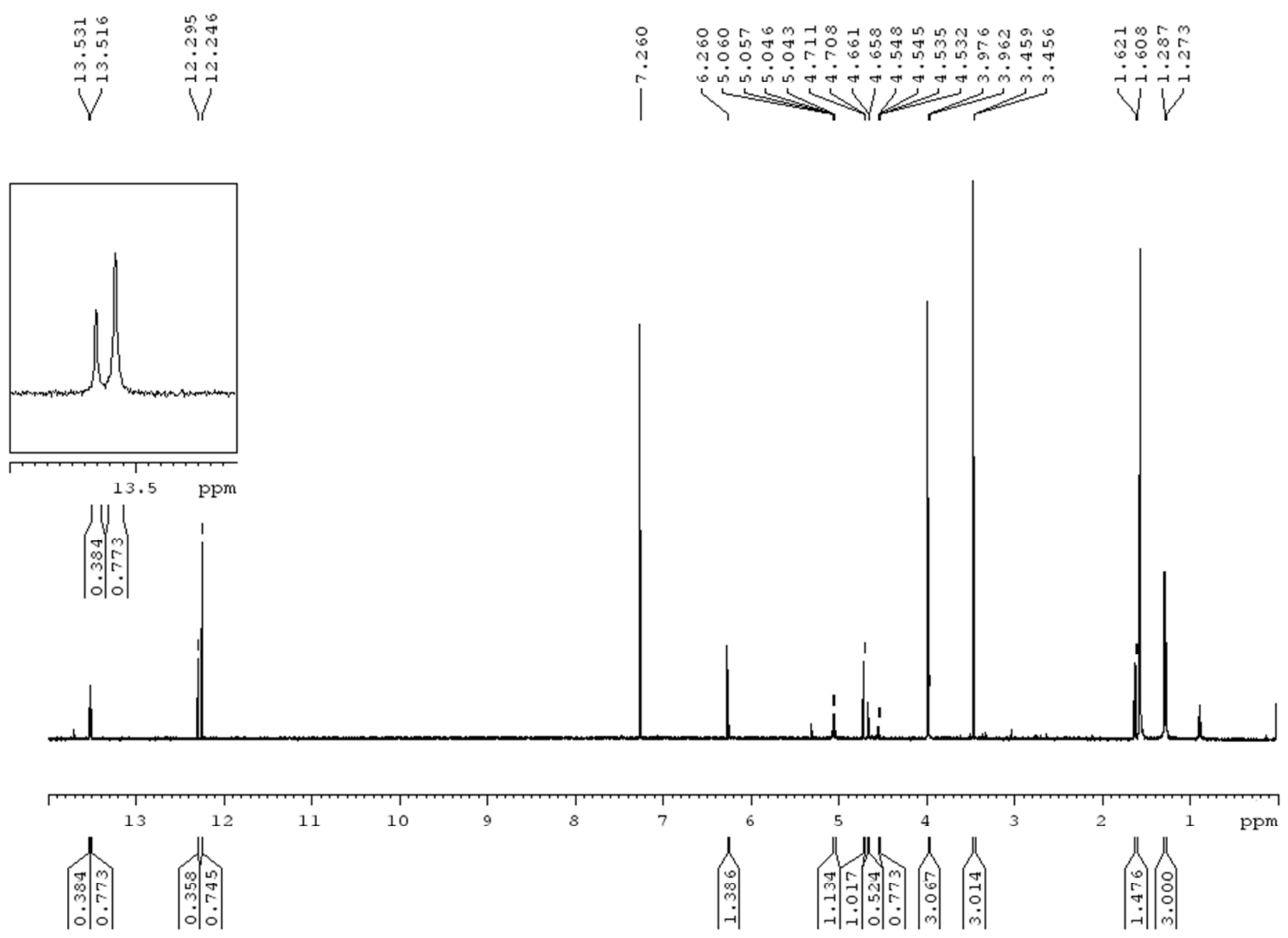
S11. COSY spectrum $\left(\mathrm{CDCl}_{3}, 500 \mathrm{MHz}\right)$ of 2

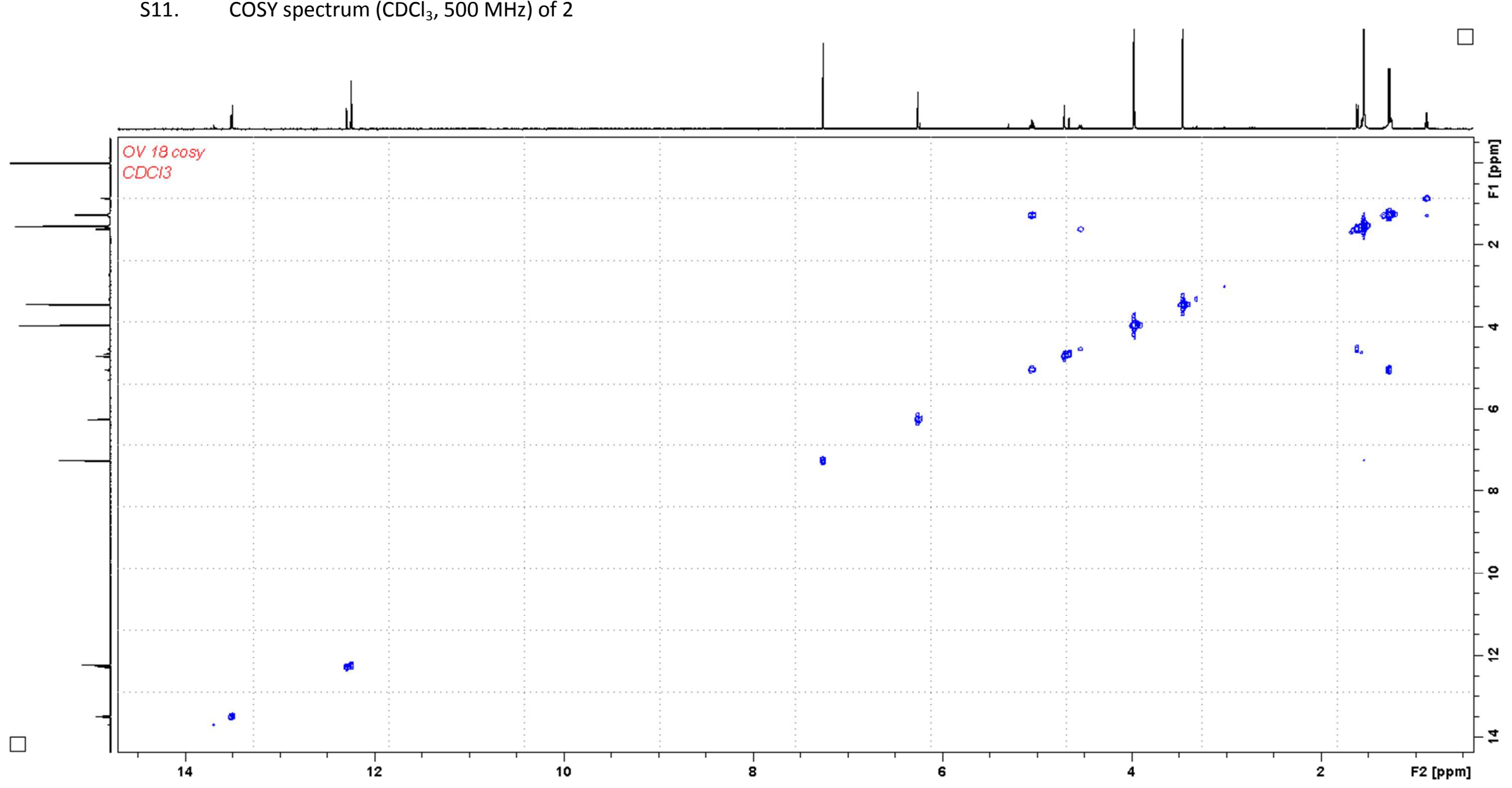




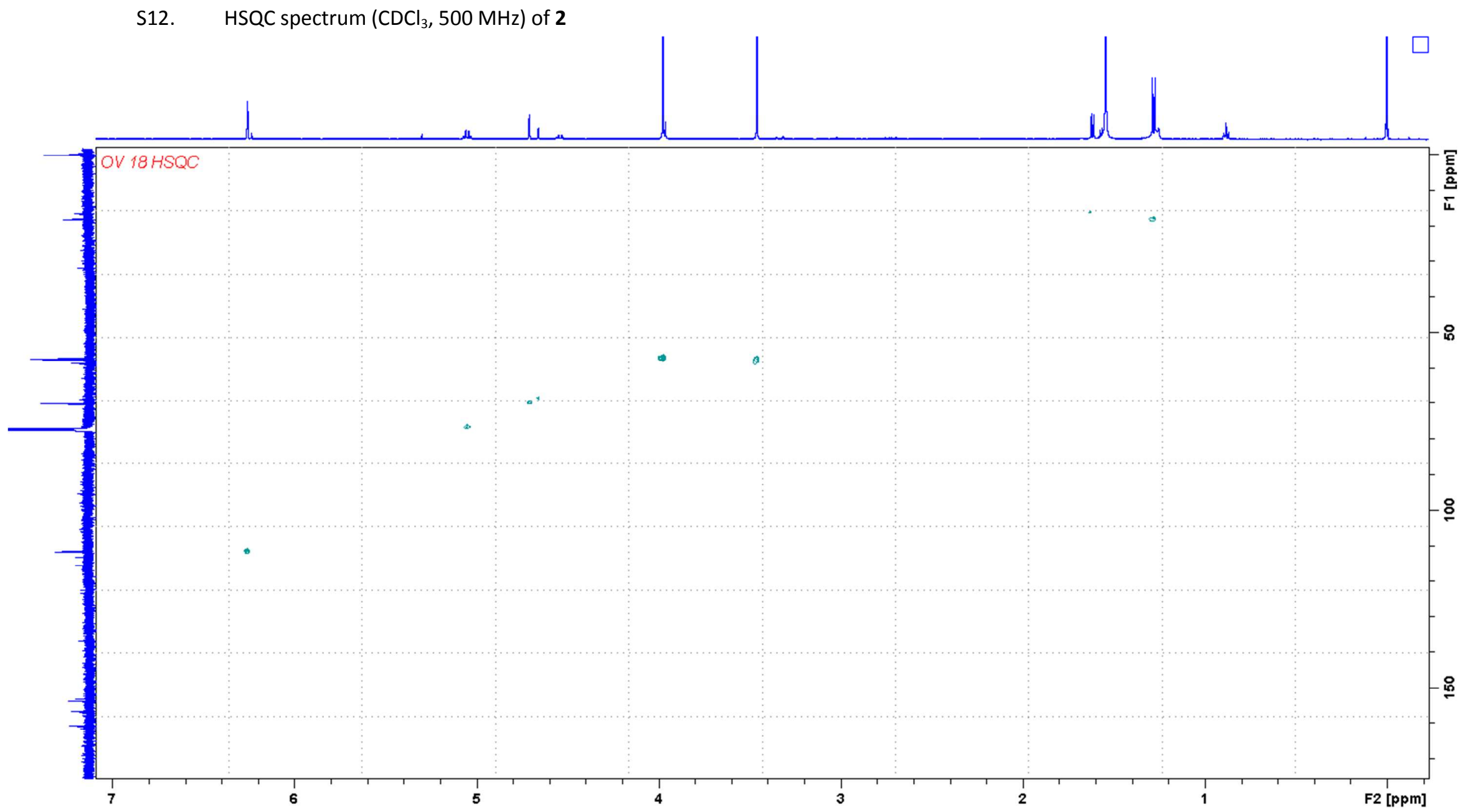


S13. $\mathrm{HMBC}$ spectrum $\left(\mathrm{CDCl}_{3}, 500 \mathrm{MHz}\right)$ of 2

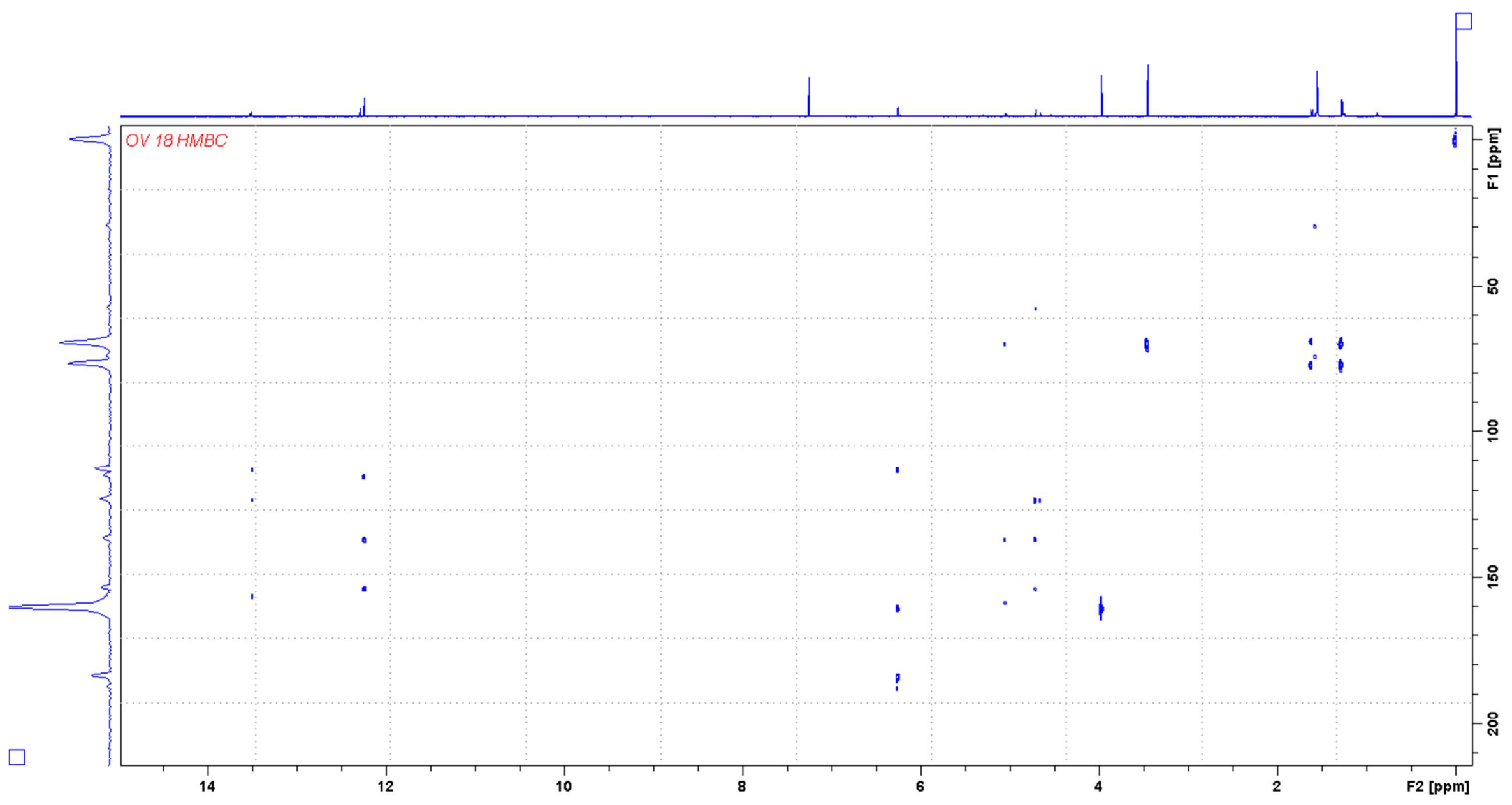




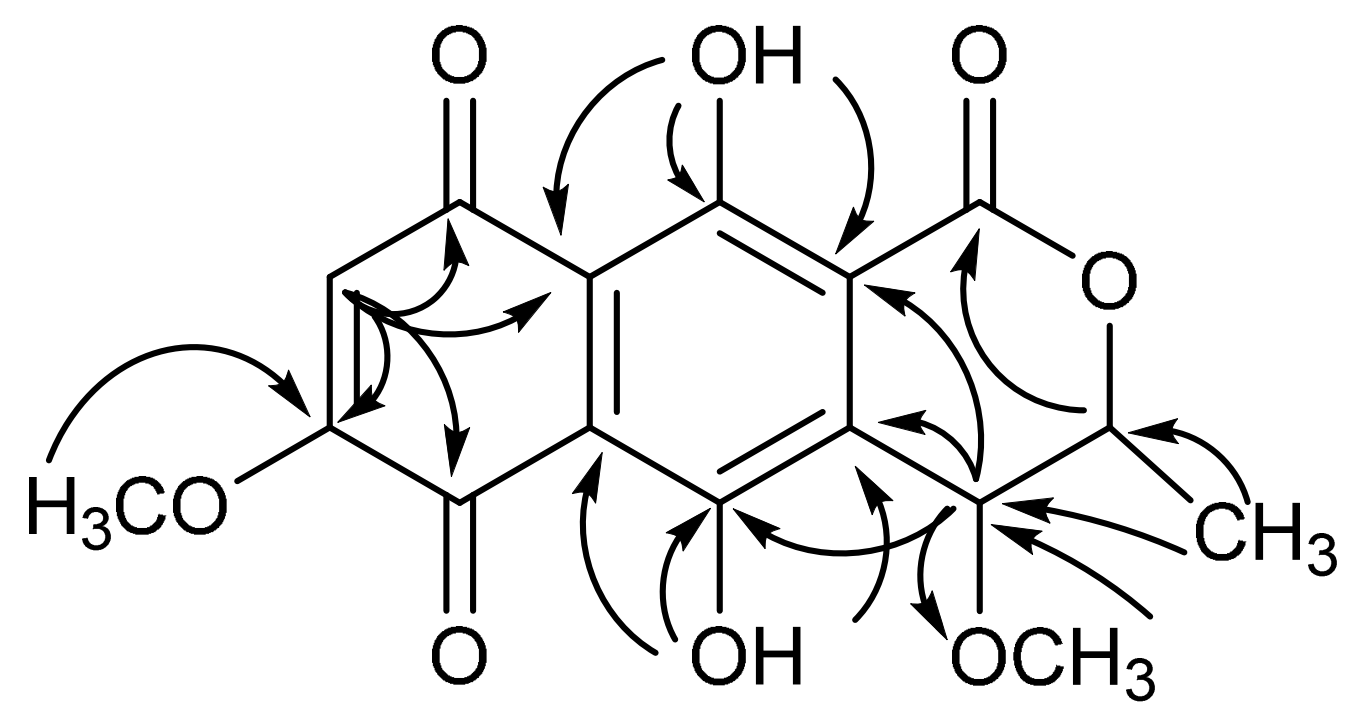

$\rightarrow \mathrm{HMBC}$ 
S15. ${ }^{1} \mathrm{H} \mathrm{NMR}\left(\mathrm{CDCl}_{3}, 500 \mathrm{MHz}\right)$ of 3
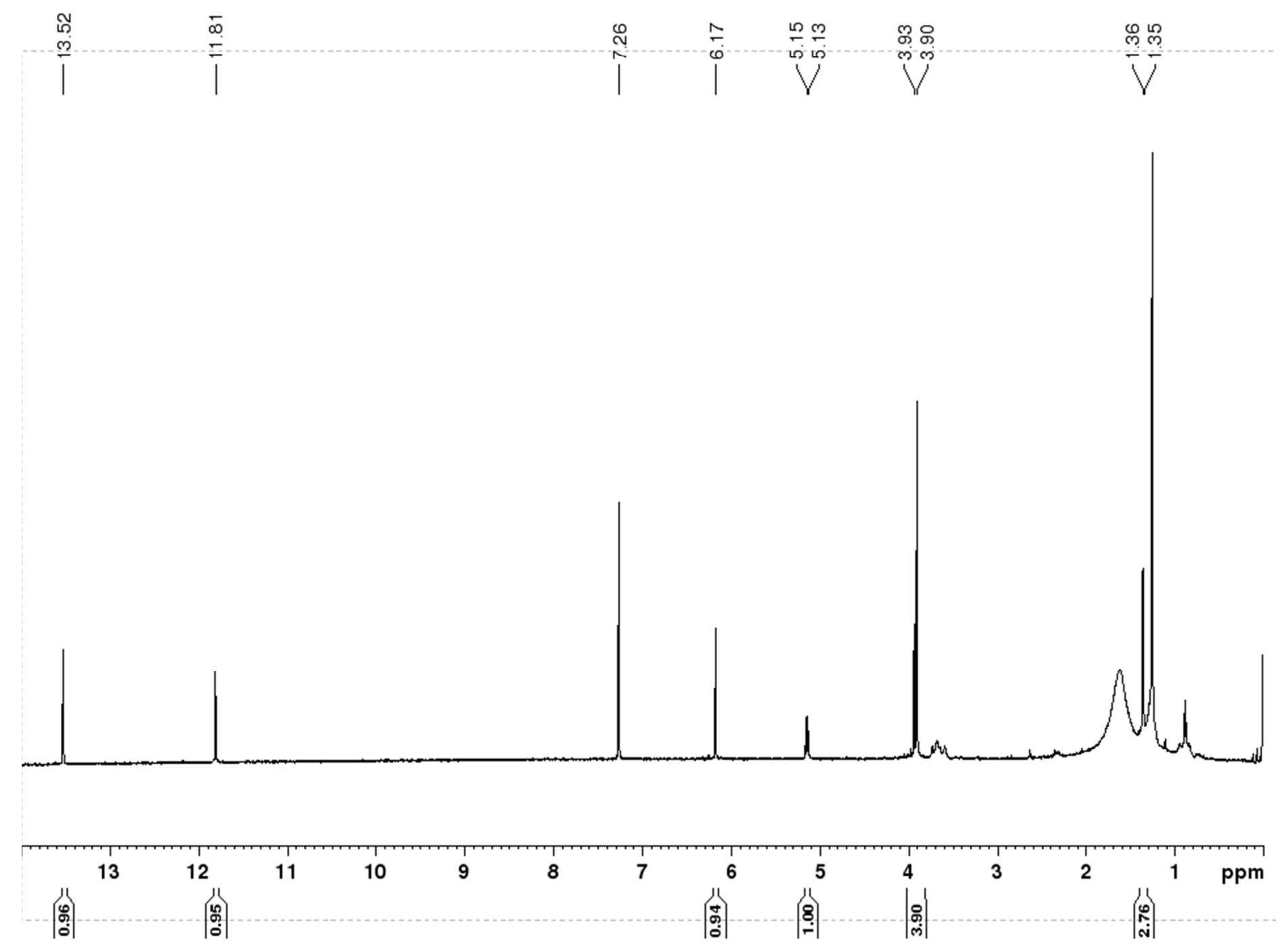
S16. HSQC spectrum $\left(\mathrm{CDCl}_{3}, 500 \mathrm{MHz}\right)$ of $\mathbf{3}$

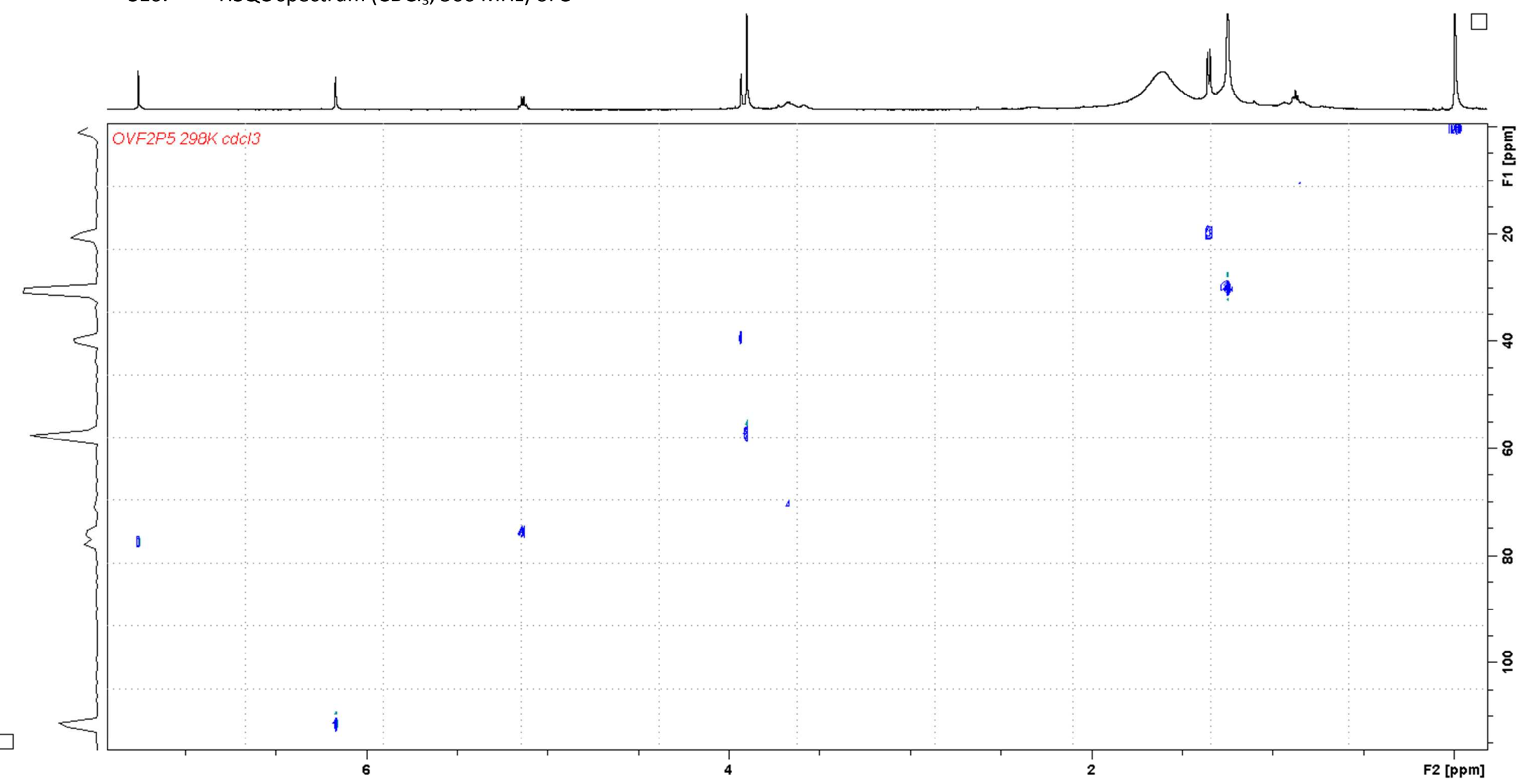


S17. $\mathrm{HMBC}$ spectrum $\left(\mathrm{CDCl}_{3}, 500 \mathrm{MHz}\right)$ of 3

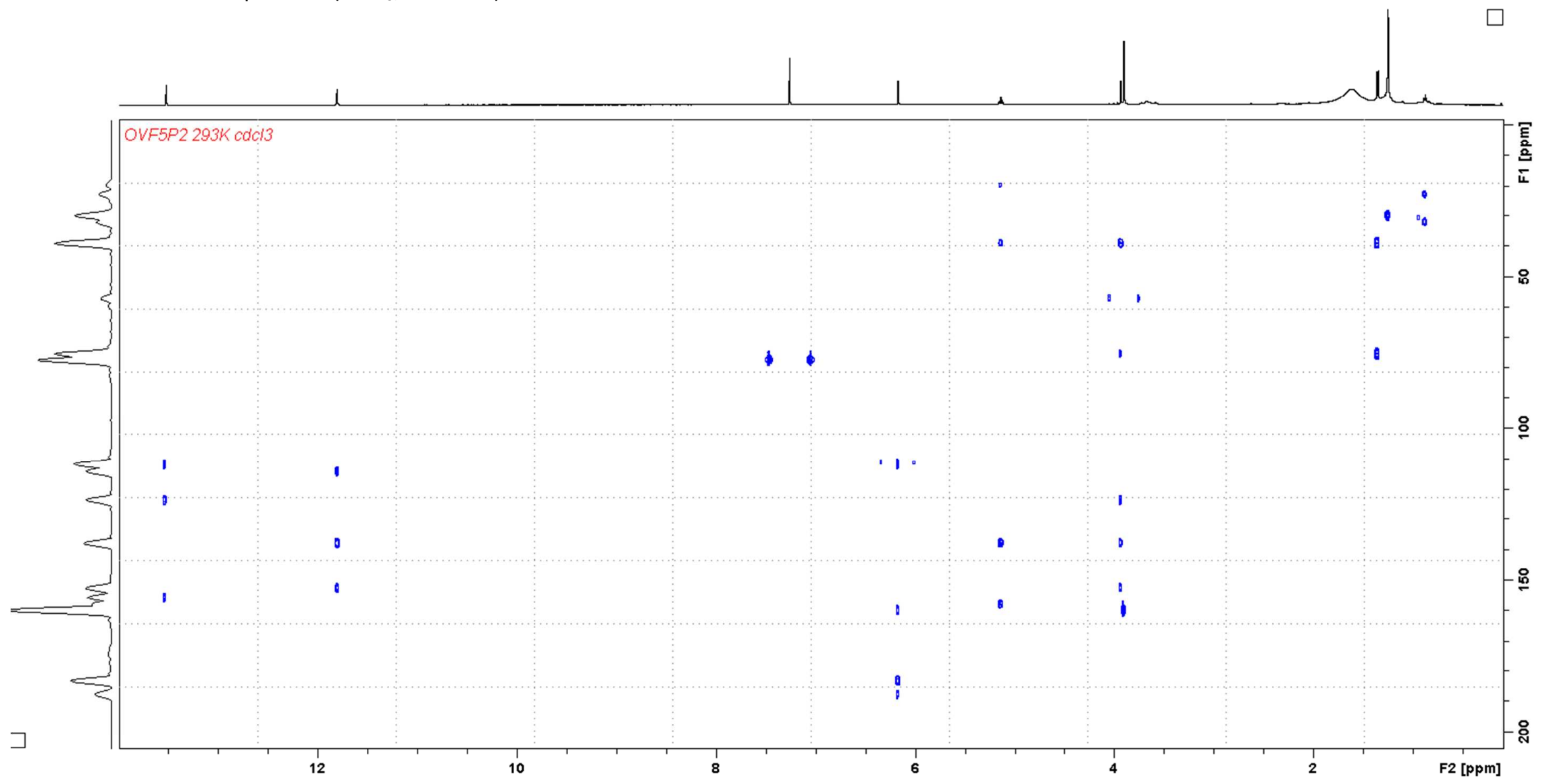


S18. HMBC (arrows) correlations of 3

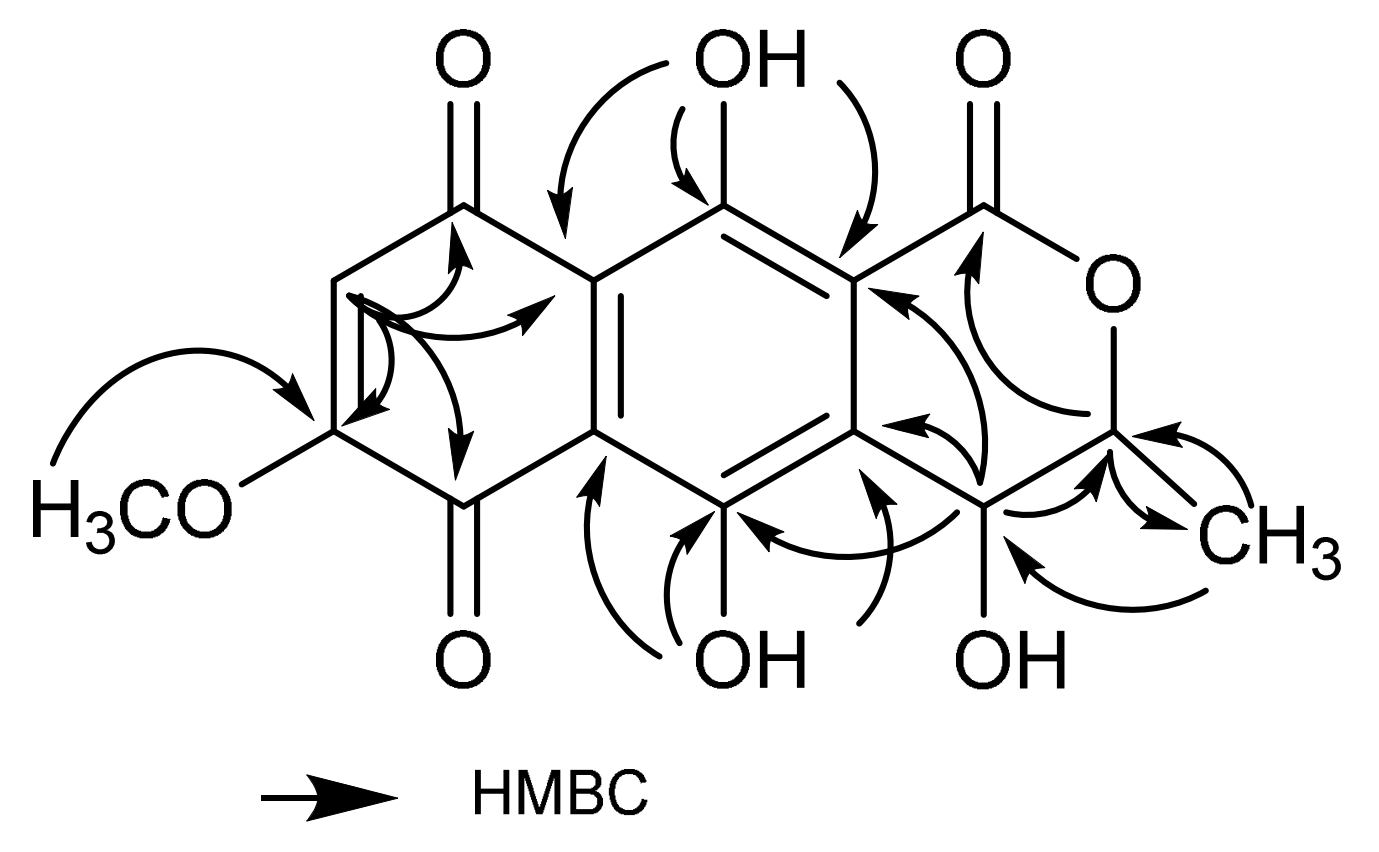


S19. ${ }^{1} \mathrm{H} \mathrm{NMR}\left(\mathrm{CDCl}_{3}, 500 \mathrm{MHz}\right)$ of 4

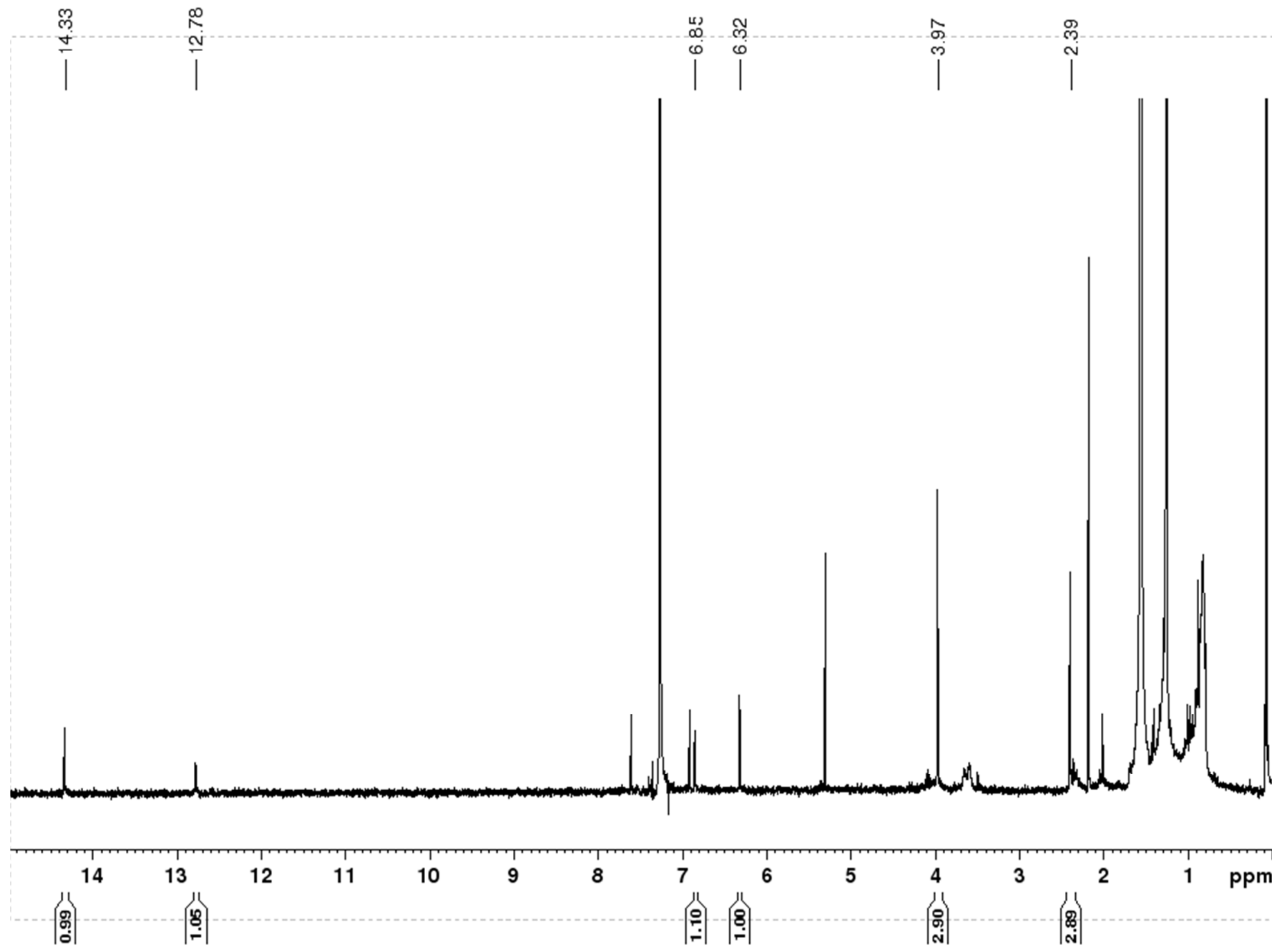




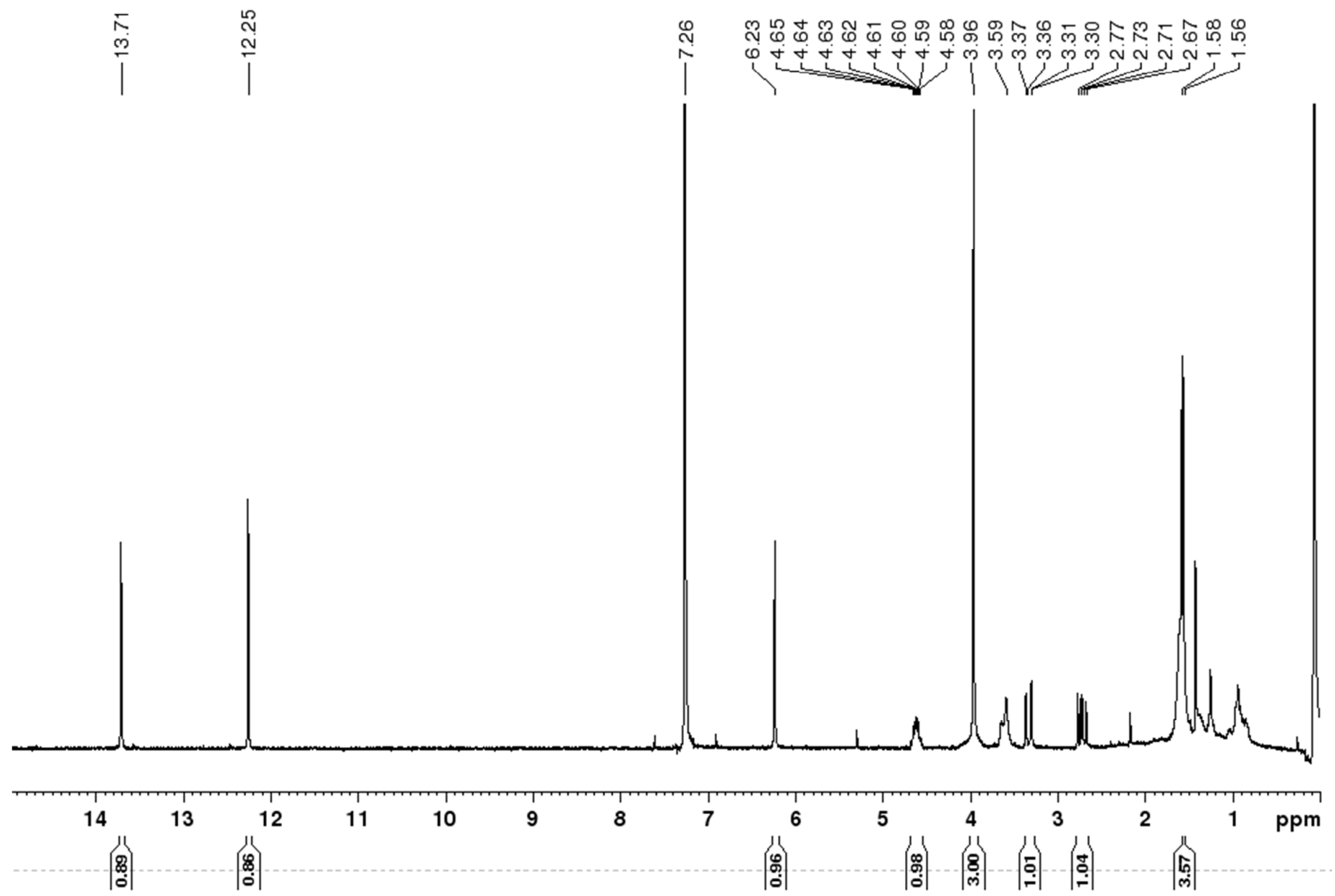


S21.

Cytotoxicity of $\mathbf{5}$ using a panel of 7 cell lines

\begin{tabular}{|c|c|c|c|c|c|c|c|}
\hline & \multicolumn{7}{|c|}{$\mathrm{IC}_{50}(\mu \mathrm{M})$ of compounds } \\
\hline & Huh7D12 & Caco2 & MDA-MB-231 & HCT116 & PC3 & NCI-H2 & Fibroblasts \\
\hline Haemoventosin (5) & 3 & 4 & 10 & 2.6 & 4 & 2.5 & 4 \\
\hline Roscovitin & 15 & 16 & 15 & 9 & 12 & 18 & 7 \\
\hline
\end{tabular}

